\title{
Компмексные исправительные учреждения на современном этапе реформирования уголовно-исполнительной системы Российской Федерации
}

\author{
В. Е. ЮЖАНИН \\ Юридический институт Рязанского государственного университета \\ им. С. А. Есенина, г. Рязань, Российская Федерация \\ ORCID: https://orcid.org/0000-0003-3123-1293, e-mail: yuzhanin1950@mail.ru
}

\section{Д. В. ГОРБАНЬ}

Санкт-Петербургский университет ФСИН России, г. Санкт-Петербург, Российская Федерация

ORCID: https://orcid.org/0000-0002-9442-7712, e-mail: dimas8807@mail.ru

\begin{abstract}
Ре фер ат
Введение: статья посвящена вопросам создания исправительных учреждений объединенного типа в соответствии с действующим уголовно-исполнительным законодательством и Концепцией развития уголовно-исполнительной системы Российской Федерации до 2030 г. Создание таких учреждений соответствует современной уголовно-исполнительной политике, но требует научной проработки. Актуальность статьи также определяется современными тенденциями пенитенциарной науки и практики. Цель: на основе обобщения и анализа официальных статистических данных, теоретических и научных источников, мнений ученых-пенитенциаристов комплексно раскрыть перспективы создания учреждений объединенного типа на современном этапе развития уголовно-исполнительной системы Российской Федерации. Методы: при написании статьи использовался диалектический метод научного познания, а также научные методы познания: сравнительно-правовой, индукции, дедукции, анализа, синтеза, статистический. Результаты: по результатам проведенного исследования авторами разработана теоретическая модель комплексного исправительного учреждения (учреждения объединенного типа). Каждому участку учреждения дана подробная характеристика. Теоретическая модель комплексного исправительного учреждения (учреждения объединенного типа) соответствует положениям действующего законодательства, перспективам его развития до 2030 г., развивает и дополняет их. Выводы: для развития исправительных учреждений объединенного типа предлагается закрепить в уголовно-исполнительном законодательстве предложенную авторами теоретическую модель комплексного исправительного учреждения.

Ключевые слова: исправительное учреждение; мультирежимность; реформирование; концепция; осужденный; комплексное учреждение; гибридное учреждение.
\end{abstract}

12.00.08 - Уголовное право и криминология, уголовно-исполнительное право.

Для цити ров ания : Южанин В. Е., Горбань Д. В. Комплексные исправительные учреждения на современном этапе реформирования уголовно-исполнительной системы Российской Федерации, Пенитенциарная наука, 2021, т. 15, № 4 (56), c. 733-741. DOI 10.46741/2686-9764-2021-15-4-733-741.

\section{Complex Correctional Institutions at the Present Stage of Reforming the Penal Enforcement System of the Russian Federation}




\title{
VYACHESLAV E. YUZHANIN
}

Law Institute of the Ryazan State University named for S.A. Yesenin, Ryazan, Russian Federation

ORCID: https://orcid.org/0000-0003-3123-1293, e-mail: yuzhanin1950@mail.ru

\section{DMITRII V. GORBAN'}

Saint Petersburg University of the Federal Penitentiary Service of Russia, Saint Petersburg, Russian Federation

ORCID: https://orcid.org/0000-0002-9442-7712, e-mail: dimas8807@mail.ru

\begin{abstract}
Introduction: the article is devoted to the creation of correctional institutions of combined type with regard to the current penal enforcement legislation and the Concept for the development of the penal enforcement system of the Russian Federation up to 2030. The foundation of correctional institutions of this type corresponds to the modern penal enforcement policy of the Russian Federation, but requires scientific study. The relevance of the presented article is also determined by modern trends in penitentiary science and practice. Purpose: on the basis of generalization and analysis of official statistical data, theoretical and scientific sources, findings and approaches of scientists-penitentiaries, to comprehensively reveal the prospects for establishing institutions of combined type at the current stage of the RF penal enforcement system development. Methods: the dialectical method of scientific cognition was used when writing a scientific article. The following scientific methods of cognition were also applied: comparative law, induction, deduction, analysis, synthesis, and statistical. Results: in the course of the study and based on its results, the authors developed a theoretical model of a complex correctional institution (institution of combined type), which includes separate areas proposed and scientifically justified by the authors. Each area of the combined type institution selected by the authors is described separately and in detail. The theoretical model of a complex correctional institution (institution of combined type) corresponds to the provisions of the current legislation, as well as the prospects for its development up to 2030, and also widens and complements them. Conclusions: in order to capture correctional facilities of a combined type in the RF penal enforcement legislation, it is proposed to enshrine the theoretical model of a complex correctional institution proposed by the authors in the corresponding articles.

K e y w o r d s : correctional facility; multi-regime; reforming; concept; convict; complex institution; hybrid institution.
\end{abstract}

12.00.08 - Criminal law and criminology; panel enforcement law.

For c itation: Yuzhanin V.E., Gorban' D.V. Complex correctional facilities at the present stage of reforming the penal enforcement system of the Russian Federation, Penitentiary Science, 2021, vol. 15, no. 4(56), pp. 733-741. DOI 10.46741/2686-9764-202115-4-733-741.

\section{Введение}

Реформирование уголовно-исполнительной системы Российской Федерации на современном этапе ее развития предполагает ряд перспективных направлений модернизации, в том числе совершенствование механизма отбывания наказания в виде лишения свободы путем создания комплексных исправительных учреждений (исправительных учреждений объединенного типа).

По состоянию на 01.09.2021 в учреждениях уголовно-исполнительной системы содержатся около 470 тыс. чел., в исправительных учреждениях находятся около 360 тыс. чел. [5]
По данным ФСИН России, в первое полугодие 2021 г. отмечалась положительная динамика снижения численности взрослых осужденных, содержащихся в исправительных учреждениях. Уменьшение численности осужденных к лишению свободы предполагает и сокращение количества исправительных учреждений [8].

В этой связи полагаем, что одно базовое исправительное учреждение может объединять в себе несколько видов режимов, а в перспективе исполнять несколько видов уголовных наказаний (например, лишение свободы на определенный срок и пожизненное лишение свободы). 


\section{Результаты}

Концепция мультирежимности (гибридности) исправительных учреждений достаточно активно обсуждается в научной литературе. Тенденцию укрупнения исправительных учреждений ученые именуют как гибридность и мультирежимность. Так, P. 3. Усев, например, говорит о межвидовой и внутривидовой гибридности [10, с. 32].

Предполагается, что гибридное исправительное учреждение будет сочетать в себе различные виды исправительных учреждений, а мультирежимное - различные виды режимов отбывания уголовных наказаний [15, c. 105].

В данном контексте В. А. Уткин говорит о процессе поляризации исправительных учреждений. Мы согласны с позицией профессора об особой роли колоний строгого режима, на базе которых предполагается создание учреждений объединенного типа [14, с. 101].

По официальной статистике на 01.01.2021, система исправительных учреждений представлена 816 учреждениями, из них: 186 следственных изоляторов, 75 ПФРСИ, 8 тюрем, 528 исправительных колоний (169 общего режима, 228 строгого режима, 37 особого режима, в том числе для осужденных к пожизненному лишению свободы).

Таким образом, количество исправительных колоний строгого режима на сегодняшний день составляет около $43 \%$ от общего количества исправительных колоний и около 28 \% от общего числа исправительных учреждений. Полагаем, что при создании учреждений объединенного типа необходимо использовать потенциал всех имеющихся в уголовно-исполнительной системе Российской Федерации исправительных колоний всех видов режима.

Правоприменительная практика также идет по пути использования имеющегося потенциала исправительных колоний. Так, первое исправительное учреждение объединенного типа предполагается создать в порядке эксперимента в УФСИН России по Калужской области. Ожидается, что оно будет включать в себя все виды режимов, производство, медицинский участок, дом ребенка, а также городок для сотрудников [9].

Мы предлагаем именовать гибридные, мультирежимные исправительные учреждения комплексными [1, с. 39]. Во-первых, данный термин объединяет в себе все виды мультирежимности и гибридности, о кото- рых говорится в научной литературе. Вовторых, он более соответствует позиции законодателя и правоприменителя, согласно которой данный вид именуется учреждениями объединенного типа.

Согласно распоряжению Правительства Российской Федерации от 29.04.2021 № 1138-р «Об утверждении Концепции развития уголовно-исполнительной системы Российской Федерации на период до 2030 года» в числе основных направлений совершенствования и развития пенитенциарной системы выделяется разработка и реализация проекта создания учреждения объединенного типа (разд. VI и VII).

Основными целями создания учреждений объединенного типа являются:

- сосредоточение нескольких исправительных учреждений и следственного изолятора в едином центре;

- модернизация и унификация имеющихся технологий;

- направленность на клиентоцентричный подход и др.

Разработку и реализацию проекта создания учреждения объединенного типа предполагается завершить к 2024 г.

Занимаемая нами позиция о создании учреждений комплексного типа поддерживается и другими учеными-пенитенциаристами

Так, И. Н. Коробова и Д. А. Середохин говорят о том, что переход к комплексным исправительным учреждениям на базе исправительных колоний является наиболее оптимальным, так как предусматривает не глобальную перестройку существующих учреждений, а лишь рациональное использование территорий, строений и сооружений с небольшими, по сравнению с перестройкой в тюрьмы, изменениями [3; 4].

Тенденция комплексности исправительных учреждений была заложена в УИК РФ в 2001 г. [13, с. 105]. С данного момента в него вносились определенные изменения, предусматривающие функционирование на базе одной исправительной колонии нескольких видов изолированных участков с различными видами режима и различными видами исправительных учреждений. Данная тенденция начала свою законодательную и правоприменительную реализацию на текущем этапе развития уголовно-исполнительной системы Российской Федерации.

Необходимо отметить, что изучаемый нами вопрос не противоречит международ- 
ным нормативным правовым документам. Так, в правиле 93 Минимальных стандартных правил в отношении обращения с заключенными 2015 г. говорится о том, что работу с разными категориями заключенных следует вести по мере возможности в разных отделениях одного и того же тюремного учреждения.

Таким образом, как отмечает В. А. Уткин, международные акты вполне допускают и даже предполагают полиструктурность и связанную с ней мультирежимность пенитенциарных учреждений [11; 12].

Положительный зарубежный опыт некоторых стран свидетельствует о применении вышеуказанной нормы международного документа и создании на базе тюрем участков с различными видами режимов, различными видами исправительных учреждений.

Данный положительный опыт широко применяется в Германии, Финляндии, Австрии и других зарубежных странах [21].

\section{Выводы}

На основании анализа научной литературы, официальных статистических данных ФСИН России, тенденций современной уголовно-исполнительной политики и правоприменительной практики нами разработана авторская теоретическая модель комплексного исправительного учреждения (учреждения объединенного типа).

В данную модель включаются следующие участки:

1) адаптационный - для вновь прибывших осужденных [6, с. 62];

2) интенсивного исправительного воздействия - для осужденных, распределенных из адаптационного участка;

3) камерного содержания - для нарушителей установленного порядка отбывания наказания, а также для реализации права осужденных на безопасность в предусмотренных законодательством случаях;

4) медицинский - для оказания медицинской помощи осужденным и реализации их соответствующих прав в данном направлении;

5) ПФРСИ - для содержания лиц, которым назначена мера пресечения в виде заключения под стражу;

6) исправительный центр - для исполнения уголовного наказания в виде принудительных работ;

7) социальной адаптации - для реализации соответствующей задачи уголовно-исполнительного законодательства, а также для подготовки осужденных к предстоящему освобождению.

Рассмотрим назначение каждого из обозначенных участков.

Адаптационный участок. Предназначен для содержания прибывших в исправительное учреждение осужденных, их подготовки и адаптации к условиям отбывания наказания. В соответствии со ст. 79 УИК РФ прибывшие осужденные помещаются в карантинное отделение на срок до 15 суток, где они находятся на обычных условиях отбывания наказания. По сути, это отделение можно назвать медицинским, а не адаптационным. Осужденные, содержащиеся в нем, проходят полное медицинское освидетельствование, с ними проводят ознакомительные мероприятия представители всех отделов и служб исправительного учреждения. Затем по решению комиссии они направляются в соответствующие отряды.

На практике выходит, что за такой короткий период (15 суток) личность осужденного изучить не удается, а он сам не успевает адаптироваться. Полагаем, что необходим адаптационный период, рассчитанный на 1,5-3 месяца (в зависимости от категории осужденных), в течение которого будут реализованы мероприятия по включению осужденного в жизнь колонии. Указанные мероприятия должны проводиться психологом, который в конечном итоге, изучив личность осужденного, сможет составить программу его ресоциализации.

Опыт функционирования адаптационных отрядов в России имеется (в Челябинской, Омской областях, Республике Мордовии и др.), и он показывает, что осужденные, содержавшиеся в них, гораздо реже нарушают режим, быстрее становятся на путь исправления. Данный факт также подтверждается в диссертационном исследовании Е. Е. Новикова [7, с. 20].

В настоящее время при приеме осужденных актуальной становится проблема обеспечения их прав, личной безопасности. Изучив прибывшего и определив его в ту или иную классификационнуюгруппу по степени опасности, можно направить его для дальнейшего отбывания наказания или в облегченные условия, или в строгие условия, или в участок с камерным содержанием. Можно сразу поставить его на профилактический учет.

Идея раздельного содержания лиц, стремящихся к исправлению, и осужденных, 
которые нацелены на притеснение других осужденных, неповиновение администрации, дальнейшую криминальную деятельность, может быть реализована на раннем этапе, то есть во время нахождения в адаптационном участке. Все это должно способствовать созданию благоприятных условий ресоциализации основной массы осужденных в местах лишения свободы [18, c. 148].

Участок интенсивного исправительного воздействия. Это основной участок в исправительном учреждении, в нем должны находиться осужденные, отбывающие наказание в обычных и облегченных условиях. Начальный этап отбывания наказания сменяется основным, когда осужденные переводятся из адаптационного участка в участок интенсивного исправительного воздействия. В обычных условиях находится основная масса осужденных.

По состоянию на 01.01.2021 в исправительных колониях в обычных условиях отбывания наказания содержалось около $79 \%$ осужденных, в облегченных - 12 \%, в строгих $-9 \%[5]$.

По нашему мнению, базовыми условиями отбывания наказания в исправительных колониях должны стать облегченные условия. Дело в том, что на обычных условиях до 80 \% осужденных характеризуются положительно или нейтрально. Если они не имеют взысканий, то, согласно действующему законодательству, их можно переводить в облегченные условия по отбытии установленного срока.

Обычные условия должны восприниматься в рамках начального этапа отбывания наказания, имеющего основной задачей адаптацию осужденных к жизнедеятельности исправительного учреждения и испытание их на предмет последующего поведения в учреждении. В случае если они не имеют взысканий при нахождении в обычных условиях, то могут быть переведены в облегченные условия. В соответствии с действующим законодательством это может произойти по истечении 6, 9 и 12 месяцев соответственно в колониях общего, строгого и особого режимов (ч. 2 ст. 120, ч. 2 ст. 122, ч. 2 ст. 124 УИК РФ). Но по каким-то причинам администрация не стремится переводить осужденных в облегченные условия. К тому же осужденные в облегченных и обычных условиях содержатся, как правило, вместе. На практике кроме дополнительного расходования денег, увеличения количества посылок и свиданий они не испытывают существенных изменений условий отбывания наказания.

В современных условиях доминантной является идея раздельного содержания лиц, стремящихся к исправлению. Так, 67 \% опрошенных нами сотрудников исправительных учреждений поддержали эту идею. Мы имеем в виду категорию лиц, которые достигли высокого уровня исправления, но не отбыли положенного срока для условнодосрочного освобождения.

В участке интенсивного содержания должен быть выделен отдельный участок покомнатного содержания осужденных с высоким уровнем исправления. Этот режим может именоваться льготным, и переводиться на него могут осужденные, которые доказали свое исправление на облегченных условиях и заключили своеобразный компромиссный договор с администрацией исправительного учреждения, предусматривающий обоюдные права и обязанности [20, с. 10].

Полагаем, что на льготных условиях должен быть установлен режим саморегуляции поведения осужденных, максимально исключающий принуждение, когда администрация использовала бы не разрешительно-принудительный метод регулирования поведения, а оказывала бы им помощь. Льготный режим должен стимулировать поведение осужденных, находящихся в облегченных условиях [17, с. 142].

Участок льготных условий отбывания наказания должен выполнять основное предназначение - постепенную адаптацию осужденных к условиям условно-досрочного освобождения.

Участок камерного содержания. Здесь предполагается размещать помещения, функционирующие в режиме тюрьмы (4. 2 ст. 74 УИК РФ), ПКТ и ШИЗО. Нет необходимости создавать отдельный участок, функционирующий как тюрьма, так как условия нахождения в нем осужденных практически сходные с ПКТ. Как правило, и категории лиц, для кого они предназначены, имеют сходство - злостные нарушители режима. Равнозначны тюрьмам и ПКТ по уровню ограничительных условий и категориям лиц ЕПКТ (ст. 118 УИК РФ). Кроме того, злостным нарушителям режима могут назначаться строгие условия отбывания наказания в отдельных запираемых помещениях (п. 22 Правил внутреннего распорядка исправительных учреждений). Получается, что этой катего- 
рии лиц могут быть определены или ПКТ, или ЕПКТ, или тюрьма, или строгие условия. Начальник колонии вынужден находиться перед дилеммой: куда их направлять.

Федеральным законом от 27.12.2018 № 569-Ф3 определен тюремный режим за преступления террористической направленности, а также посягающие на государственного деятеля, сотрудника правоохранительного органа, диверсии, а также за иные особо тяжкие преступления, посягающие на государственные интересы (ч. 2, 2.1 ст. 58 УК РФ). Данную категорию лиц, на наш взгляд, следует направлять в отдельные самостоятельно функционирующие тюрьмы. В них должны находиться также лица, которым суд определил тюрьму в случае совершения особо тяжкого преступления с назначением наказания свыше пяти лет, а также и при особо опасном рецидиве преступлений.

ЕПКТ как дисциплинарную меру воздействия мы предлагаем упразднить, заменить их тюрьмами, которые могут функционировать в исправительном учреждении согласно ч. 2 ст. 74 УИК РФ. Они должны служить в большей степени мерой безопасности, куда следует размещать следующие категории: лиц, занимающих высшее положение в преступной иерархии (ст. 210.1 УК РФ); лиц с проявившимися экстремистскими устремлениями во время нахождения в исправительном учреждении; лиц, признанных злостными нарушителями режима во время отбывания наказания в исправительном учреждении, в отношении которых были безуспешно применены меры воздействия, в том числе помещение в ШИЗО, ПКТ и строгие условия. Направление в ПКТ как дисциплинарная мера воздействия предусмотрено для злостных нарушителей режима, признанных таковыми в период и после содержания их в строгих условиях отбывания наказания. В отношении злостных нарушителей режима в случае непрекращения ими противоправной деятельности в пределах одного учреждения должен быть предусмотрен комплекс дисциплинарных мер воздействия: строгие условия - ПКТ - тюрьма. Строгие условия являются более мягкой мерой, отличаются тем, что осужденные проживают не в камеpax, а в общежитиях в запираемых помещениях. При переводе в ПКТ они попадают в камерные условия на срок до шести месяцев. При последующем переводе в тюрьму они также содержатся в камерах, но более длительный срок - до трех лет. При сохраняющемся противоправном поведении постепенно ужесточаются условия дисциплинарного воздействия. Причем в уголовно-исполнительном законодательстве следует определить полномочия начальника колонии по переводу в тюрьму в пределах учреждения с согласия общественной наблюдательной комиссии, а не передавать это на усмотрение суда.

Таким образом, участок камерного содержания должен выполнять роль меры безопасности и меры дисциплинарного воздействия.

Как уже отмечалось, участок строгих условий отбывания наказания предназначен для лиц, признанных злостными нарушителями режима (например, ч. 3 и 4 ст. 120 УИК РФ). Строгие условия должны быть первоначальной мерой, в соответствии с которой злостному нарушителю режима изменяются условия отбывания наказания в худшую сторону внутри исправительного учреждения. Согласно п. 22 Правил внутреннего распорядка исправительных учреждений они содержатся в помещениях, оборудованных согласно нормам действующего законодательства.

Эти запираемые помещения должны быть расположены в отдельных изолированных участках. Главное в отбывании наказания в этих помещениях - это ограничительные условия, связанные с изоляцией находящихся в них осужденных в запираемых помещениях. Для них разрешен выход за пределы этих помещений лишь в предусмотренных законодательством случаях. Поэтому этот участок функционирует автономно и должен быть изолирован от других участков.

Медицинский участок. Предусмотрен для медицинского и санитарно-гигиенического обслуживания осужденных, содержащихся в исправительном учреждении (ч. 2 ст. 101 УИК РФ). В составе некоторых исправительных учреждений могут организовываться отдельные участки, функционирующие как лечебно-профилактические больницы, а в женских колониях - дома ребенка, родильные отделения, молочные кухни.

Медико-санитарная часть располагается в отдельном изолированном участке, огороженном от другой территории забором сплошного заполнения. Доступ осужденных в него ограничен, установлены специальные правила посещения его больными. 
Участок ПФРСИ предназначен для содержания лиц, которым назначена мера пресечения в виде заключения под стражу.

Участок исправительного центра предусмотрен для исполнения уголовного наказания в виде принудительных работ.

Участок социальной адаптации. В нем должны находиться осужденные, которые готовятся к освобождению по отбытии полного срока наказания. Для них это заключительный этап отбытия наказания.

На данном участке администрация должна проводить комплекс мероприятий, связанных с приобретением освобождаемым специальности, необходимой для устройства на работу на свободе, с решением проблем трудового и бытового устройства, налаживанием социально полезных связей осужденного с семьей и родственниками и пр.

Конечно, чтобы решить задачу полноценной социальной адаптации освобождаемого, необходимо создать для него условия полусвободы. По мнению некоторых исследований, уровень адаптации выше у тех осужденных, кто прошел через подобные условия [16, с. 163]. Особенно это касается лиц, которые отбывали длительные сроки лишения свободы.

Важно, чтобы освобождаемые были сосредоточены на адаптации, для этого они должны быть объединены в одну группу и изолированы от других осужденных в отдельном участке.

Часть 3 ст. 121 УИК РФ предусматривает для осужденных, содержащихся на облегченных условиях в колониях общего режима, возможность проживать и работать под контролем администрации за пределами исправительного учреждения в целях их успешной адаптации. Но почему только для осужденных, содержащихся в облегченных условиях и только в колониях общего режима? В данном случае законодатель руководствовался не целесообразностью, а идеей о том, что можно доверять только тем, кто проявил стремление к исправлению и кто впервые судим. Почему нельзя рассматривать эти полусвободные условия отбывания наказания за шесть месяцев до освобождения для всех категорий осужденных, на всех видах режима, за исключением тех, кто по оперативным данным представляет опасность для общества? Эти условия мы именовали бы открытыми условиями, как это предусмотрено законодательством некоторых зарубежных стран.

Для осужденных, проживающих перед освобождением в участке социальной адаптации [2; 19], в каждом виде режима исправительных колоний должны быть предусмотрены свои уровни контроля и надзора.

\section{СПИСОК ЛИТЕРАТУРЫ}

1. Горбань, Д. В. «Комплексные» исправительные учреждения в пенитенциарной системе России на современном этапе ее реформирования / Д. В. Горбань // Актуальные вопросы борьбы с преступлениями. - 2015. - № 1. - С. 3843.

2. Горбань, Д. В. Проживание осужденных за пределами исправительных учреждений как элемент прогрессивной системы отбывания лишения свободы: проблемы теории и практики : монография / Д. В. Горбань, В. Е. Южанин. Томск : Томский политехнический университет, 2016. - 191 с. - ISBN 978-5-4387-0681-6.

3. Коробова, И. Н. К вопросу о создании комплексных исправительных учреждений в Российской Федерации / И. Н. Коробова // Вестник Кузбасского института. - 2020. - № 2 (43). - С. 58-63.

4. Коробова, И. Н. Реформирование исправительных колоний как основа изменения системы исправительных учреждений / И. Н. Коробова, Д. В. Середохин // Уголовно-исполнительная система на современном этапе и перспективы ее развития : сборник тезисов выступлений и докладов участников международной научно-практической конференции : в 6 т. - Рязань : Академия ФСИН России, 2020. - Том 1. - С. 105-111.

5. Краткая характеристика уголовно-исполнительной системы Российской Федерации. - URL: https://fsin.gov.ru/ structure/inspector/iao/statistika/Kratkaya\%20har-ka\%20UIS/ (дата обращения: 14.09.2021).

6. Новиков, Е. Е. Первоначальная адаптация осужденных в карантинном отделении исправительных учреждений / Е. Е. Новиков // Вестник Кузбасского института. - 2015. - № 4 (25). - С. 62-66.

7. Новиков, Е. Е. Правовое регулирование направления осужденных в исправительные учреждения, их приема и размещения : автореферат на соискание ученой степени кандидата юридических наук / Новиков Егор Евгеньевич. - Рязань, 2011. - 24 с.

8. Обзор информации о деятельности ФСИН России за 1 полугодие 2021 года // Федеральная служба исполнений наказаний : официальный сайт. - URL: https://fsin.gov.ru/statistics/obzor-informatsii-o-deyatelnosti-fsin-rossii-za-ipolugodie-2021-goda.php, свободный (дата обращения: 14.09.2021).

9. Первое мультиучреждение ФСИН может появиться в ближайшем к Москве регионе // Российская газета : официальный сайт. - URL: https://rg.ru/2021/03/12/reg-cfo/pervoe-multiuchrezhdenie-fsin-mozhet-poiavitsia-v-blizhajshemk-moskve-regione.html (дата обращения: 28.09.2021).

10. Усев, Р. З. Перспективы развития системы гибридных исправительных учреждений в аспекте обеспечения безопасности уголовно-исполнительной системы / Р. З. Усеев // Ведомости уголовно-исполнительной системы. 2017. - № 4 (179). - С. 30-35. 
11. Уткин, В. А. Гибридные исправительные учреждения и международные стандарты / В. А. Уткин // Уголовно-исполнительное право. - 2014. - № 2 (18). - С. 7-11.

12. Уткин, В. А. Минимальные стандартные правила Организации Объединенных Наций и смена уголовно-исполнительных парадигм / В. А. Уткин // Международный пенитенциарный журнал. - 2016. - № 1. - С. 67-70.

13. Уткин, В. А. Назначение наказаний и уголовно-исполнительная система / В. А. Уткин // Вестник Кузбасского института. - 2016. - № 4 (29). - С. 104-109.

14. Уткин, В. А. Новая концепция развития уголовно-исполнительной системы: основания и принципы / В. А. Уткин // Вестник Кузбасского института. - 2018. - № 4 (37). - С. 99-103.

15. Уткин, В. А. «Гибридные» и «мультирежимные» пенитенциарные учреждения: преимущества и риски / В. А. УТкин, М. В. Киселев, С. М. Савушкин // Вестник Томского государственного университета. Серия: Право. - 2018. № 29. - С. 103-113.

16. Цибульский, В. В. Социально-педагогическая деятельность социального работника с осужденными, пользующимися правом передвижения без конвоя за пределами исправительных учреждений : диссертация на соискание ученой степени кандидата педагогических наук / Цибульский Виктор Викторович. - Москва, 2003 - 190 с.

17. Южанин, В. Е. Характеристика основного этапа отбывания наказания осужденными в исправительных учреждениях / В. Е. Южанин // Вестник Кузбасского института ФСИН России. - 2020. - № 1 (42). - С. 141-143.

18. Южанин, В. Е. Начальный и заключительный этапы отбывания лишения свободы: проблемы концептуального определения / В. Е. Южанин, Д. В. Горбань // Человек: преступление и наказание. - 2018. - № 2. - С. 148-150.

19. Южанин, В. Е. Проблемы создания открытых условий отбывания наказания в виде лишения свободы / В. Е. Южанин, Д. В. Горбань // Психопедагогика в правоохранительных органах. - 2020. - Том 25, № 3 (82). - С. 338-344.

20. Южанин, В. Е. Поэтапная ресоциализация положительно характеризующихся осужденных : практические рекомендации / В. Е. Южанин. - Рязань : Академия ФСИН России, - 2020. - 34 с.

21. Timofeeva, E. A. Foreign Prison Experience Resocialization of Prisoners / E. A. Timofeeva // SHS Web of Conferences. URL: https://www.shs-conferences.org/articles/shsconf/pdf/2019/03/shsconf_pedtp2018_12004.pdf (дата обращения: 14.09.2021).

\section{REFERENCES}

1. Gorban' D.V. "Complex" correctional institutions in the penitentiary system of Russia at the present stage of its reforming. Aktual'nye voprosy bor'by s prestupleniyami=Topical Issues of Combating Crimes, 2015, no. 1, pp. 38-43. (In Russ.).

2. Gorban' D.V., Yuzhanin V.E. Prozhivanie osuzhdennykh za predelami ispravitel'nykh uchrezhdenii kak element progressivnoi sistemy otbyvaniya lisheniya svobody: problemy teorii i praktiki: monografiya [Living of convicts outside correctional institutions as an element of a progressive system of serving imprisonment: problems of theory and practice: monograph]. Tomsk: Izd-vo Tomskogo politekhnicheskogo universiteta, 2016. 191 p.

3. Korobova I.N. On the issue of creating integrated correctional institutions in the Russian Federation. Vestnik Kuzbasskogo instituta=Bulletin of the Kuzbass Institute, 2020, vol. 43, no. 2, pp. 58-63. (In Russ.).

4. Korobova I.N., Seredokhin D.A. Reforming correctional colonies as a basis for changing the correctional system. In: Ugolovno-ispolnitel'naya sistema na sovremennom etape i perspektivy ee razvitiya: Sbornik tezisov vystuplenii i dokladov uchastnikov Mezhdunarodnoi nauchno-prakticheskoi konferentsii [The penal enforcement system at the present stage and prospects for its development: collection of abstracts of speeches and reports of participants of the International researchto-practice conference]. Ryazan: Akademiya FSIN Rossii, 2020. Pp. 105-111. (In Russ.).

5. Brief description of the penal enforcement system of the Russian Federation. Federal'naya sluzhba ispolnenii nakazanii: ofitsial'nyi sait [Federal Penitentiary Service of Russia: official website]. Available at: https://fsin.gov.ru/structure/inspector/ iao/statistika/Kratkaya\%20har-ka\%20UIS/ (accessed September 14, 2021).

6. Novikov E.E. Adaptation of convicts in quarantine in prison. Vestnik Kuzbasskogo instituta=Bulletin of the Kuzbass Institute, 2015, vol. 25, no. 4, pp. 62-66. (In Russ.).

7. Novikov E.E. Pravovoe regulirovanie napravleniya osuzhdennykh $v$ ispravitel'nye uchrezhdeniya, ikh priema $i$ razmeshcheniya: avtoreferat na soiskanie uchenoi stepeni kandidata yuridicheskikh nauk [Legal regulation of the transfer of convicts to correctional institutions, their reception and placement: Candidate of Sciences (Law) dissertation abstract]. Ryazan, 2011.24 p.

8. Overview of information on the activities of the Federal Penitentiary Service of Russia for the 1st half of 2021. Federal'naya sluzhba ispolnenii nakazanii: ofitsial'nyi sait [Federal Penitentiary Service of Russia: official website]. Available at: https:// fsin.gov.ru/statistics/obzor-informatsii-o-deyatelnosti-fsin-rossii-za-i-polugodie-2021-goda.php, svobodnyi. (accessed September 14, 2021).

9. The first multi-institution of the Federal Penitentiary Service may appear in the region closest to Moscow. Rossiiskaya gazeta: ofitsial'nyi sait [Russian newspaper: official website]. Available at: https://rg.ru/2021/03/12/reg-cfo/pervoemultiuchrezhdenie-fsin-mozhet-poiavitsia-v-blizhajshem-k-moskve-regione.html (In Russ.). (Accessed September 28 , 2021).

10. Useev R.Z. The hybridity of places of deprivation of liberty in the view of security of the criminal-executive system. Vedomosti ugolovno-ispolnitel'noi sistemy=Vedomosti of the Penal Enforcement System, 2017, vol. 179, no. 4, pp. 30-35. (In Russ.).

11. Utkin V.A. Hybrid correctional facilities and international standards. Ugolovno-ispolnitel'noe pravo=Penal Law, 2014, vol. 18, no. 2, pp. 7-11. (In Russ.).

12. Utkin V.A. Minimal'nye standartnye pravila organizatsii ob"edinennykh natsii i smena ugolovno-ispolnitel'nykh paradigm. Mezhdunarodnyi penitentsiarnyi zhurnal=International Penitentiary Journal, 2016, no. 1, pp. 67-70. (In Russ.).

13. Utkin V.A. Assignment of punishment and penal system. Vestnik Kuzbasskogo instituta=Bulletin of the Kuzbass Institute, 2016, vol. 29, no. 4, pp. 104-109. (In Russ.).

14. Utkin V.A. New concept of development of penal system: bases and principles Vestnik Kuzbasskogo instituta=Bulletin of the Kuzbass Institute, 2018, vol. 37, no. 4, pp. 99-103. (In Russ.).

15. Utkin V.A., Kiselev M.V., Savushkin S.M. "Hybrid" and "multi-regime" penitentiary institutions: advantages and risks. Vestnik Tomskogo gosudarstvennogo universiteta. Pravo=Tomsk State University Journal of Law, 2018, no. 29, p. 103113. (In Russ.). 
16. Tsibul'skii V.V. Sotsial'no-pedagogicheskaya deyatel'nost' sotsial'nogo rabotnika s osuzhdennymi, pol'zuyushchimisya pravom peredvizheniya bez konvoya za predelami ispravitel'nykh uchrezhdenii: dissertatsiya na soiskanie uchenoi stepeni kandidata pedagogicheskikh nauk [Social and pedagogical activity of a social worker with convicts using the right to travel without escort outside correctional institutions: Candidate of Sciences (Pedagogy) dissertation]. Moscow, 2003. 190 p.

17. Yuzhanin V.E. Characteristics of the main stage of punishment serving by convicts in correctional institutions. Vestnik Kuzbasskogo instituta=Bulletin of the Kuzbass Institute, 2020, vol. 42, no. 1, pp. 141-143. (In Russ.).

18. Yuzhanin V.E., Gorban' D.V. Initial and final stages of serving imprisonment: problems of conceptual definition. Chelovek: prestuplenie i nakazanie=Man: Crime and Punishment, 2018, no. 2, pp. 148-150. (In Russ.).

19. Yuzhanin V.E., Gorban' D.V. Institution of preparing convicts for release in the progressive system of serving the sentence of imprisonment. Psikhopedagogika v pravookhranitel'nykh organakh=Psychopedagogy in Law Enforcement, 2020, vol. 25, no. 3 (82), pp. 338-344. (In Russ.).

20. Yuzhanin V.E., Smirnov I.A. Poetapnaya resotsializatsiya polozhitel'no kharakterizuyushchikhsya osuzhdennykh: prakticheskie rekomendatsii [Step-by-step resocialization of positively characterized convicts: practical recommendations]. Ryazan: Akademiya FSIN Rossii, 2020. 34 p.

21. Timofeeva E.A. Foreign prison experience resocialization of prisoners. SHS Web of Conferences, 2019, vol. 62, pp. 1-4. DOI: https://doi.org/10.1051/shsconf/20196212004.

\section{СВЕДЕНИЯ ОБ АВТOPAX / INFORMATION ABOUT THE AUTHORS}

ВЯЧЕСЛАВ ЕФИМОВИЧ ЮЖАНИН - ДОктор ЮрИдИческих наук, профессор, профессор кафедры уголовного права и криминологии Юридического института Рязанского государственного университета им. С. А. Есенина, г. Рязань, Российская Федерация, ORCID: https:// orcid.org/0000 0003-3123-1293, e-mail: yuzhanin1950@ mail.ru

ДМИТРИЙ ВЛАДИМИРОВИЧ ГОРБАНЬ - КаНДИДат юридических наук, доцент кафедры организации исполнения наказаний юридического факультета СанктПетербургского университета ФСИН России, г. СанктПетербург, Российская Федерация, ORCID: https://orcid. org/0000-0002-9442-7712, e-mail: dimas8807@mail.ru
VYACHESLAV E. YUZHANIN - Doctor of Sciences (Law), Professor, Professor of the Department of Criminal Law and Criminology of the Ryazan State University named for S.A. Yesenin, Ryazan, Russian Federation, ORCID: https:// orcid.org/0000 0003-3123-1293, e-mail: yuzhanin1950@ mail.ru

DMITRII V. GORBAN' - Candidate of Sciences (Law), Associate Professor of the Department for Punishment Execution Organization of the Faculty of Law of the Saint Petersburg University of the Federal Penitentiary Service of Russia, Saint Petersburg, Russian Federation, ORCID: https://orcid.org/0000-0002-9442-7712, e-mail: dimas8807@mail.ru 